\title{
INHIBITION OF ANGIOTENSIN-CONVERTING ENZYME BY CAPTOPRIL: A NOVEL APPROACH TO REDUCE ISCHEMIA-REPERFUSION INJURY AFTER LUNG TRANSPLANTATION
}

Stefan Fischer, MD*

Alexandra A. MacLean, MD*

Mingyao Liu, MD, MSc

Baljit Kalirai, BSc

Shaf Keshavjee, MD, MSc, FRCSC, FACS
Objectives: Ischemia-reperfusion injury after lung transplantation involves the generation of free radicals. Captopril has been shown to be protective in models of ischemia-reperfusion injury in other organs by acting as a free radical scavenger. The purpose of this study was to assess the protective effects of captopril against ischemia-reperfusion injury and to evaluate the ability of captopril to scavenge free radicals and inhibit neutrophil activation in an experimental model of lung transplantation.

Methods: A rat single-lung transplant model was used. Donor lungs were flushed and preserved in low-potassium dextran-glucose solution with $(\mathrm{n}=5)$ and without captopril $(500 \mu \mathrm{mol} / \mathrm{L} ; \mathrm{n}=5)$ for 18 hours at $4{ }^{\circ} \mathrm{C}$ and then transplanted and reperfused for 2 hours. At the conclusion of the 2-hour reperfusion period, arterial blood gases, blood pressure, and peak airway pressure were measured. Lung tissue biopsy specimens were obtained for assessment of wet/dry weight ratios, histology, and neutrophil sequestration (myeloperoxidase activity). Lipid peroxidation $\left(\mathrm{F}_{2}\right.$-isoprostane assay) was analyzed from plasma samples and tissue lysates.

Results: The addition of captopril to the lung preservation solution significantly improved postreperfusion $\mathrm{Po}_{2}(312 \pm 63.3 \mathrm{~mm} \mathrm{Hg}$ vs $202 \pm 21.1 \mathrm{~mm}$ $\mathrm{Hg} ; P=.006)$, peak airway pressure $\left(11.4 \pm 1.1 \mathrm{~cm} \mathrm{H} \mathrm{H}_{2} \mathrm{O}\right.$ vs $15.6 \pm 1.5 \mathrm{~cm}$ $\left.\mathrm{H}_{2} \mathrm{O} ; P=.001\right)$, and wet/dry weight ratio $(4.9 \pm 0.4$ vs $15.8 \pm 10.9 ; P=.008)$. Blood pressures did not differ significantly between groups. No significant differences were seen in myeloperoxidase activity or $\mathrm{F}_{2}$-isoprostane levels.

Conclusions: The use of captopril in the preservation solution ameliorates ischemia-reperfusion injury in transplanted lungs after an extended cold preservation period. The mechanisms by which captopril is protective remain elusive but do not appear to include inhibition of neutrophil sequestration or lipid peroxidation. This novel approach to ischemia-reperfusion injury may lead to improved lung function after transplantation and provide further insight into the pathogenesis of acute lung injury. ( $\mathrm{J}$ Thorac Cardiovasc Surg 2000;120:573-80)
From the Thoracic Surgery Research Laboratory, Division of Thoracic Surgery, Toronto General Hospital Research Institute, University of Toronto, Toronto, Ontario, Canada.

Supported by grants from the National Sanitarium Association of Canada and the Canadian Cystic Fibrosis Foundation. M. Liu is a scholar of the Medical Research Council of Canada.

Received for publication Jan 18, 2000; revisions requested March 17, 2000; revisions received March 31, 2000; accepted for publication April 11, 2000.

Address for reprints: Shaf Keshavjee, MD, Director, Toronto Lung Transplant Program, Division of Thoracic Surgery, Toronto General Hospital, 200 Elizabeth St, EN10-224, Toronto, Ontario, Canada, M5G 2C4 (E-mail: shaf.keshavjee@uhn.on.ca).

${ }^{*}$ Drs Fischer and MacLean contributed equally to this work.

Copyright (c) 2000 by The American Association for Thoracic Surgery

$0022-5223 / 2000 \$ 12.00+0 \quad \mathbf{1 2 / 1 / 1 0 7 8 2 8}$

doi: $10.1067 / \mathrm{mtc} .2000 .107828$ schemia-reperfusion injury is a major contributor to early graft failure after lung transplantation. ${ }^{1}$ The clinical consequences of ischemia-reperfusion injury include prolonged requirement for assisted ventilation, need for high inspired oxygen fractions, and pulmonary edema. ${ }^{2}$ An understanding of the pathophysiology of ischemia-reperfusion injury is evolving, and the following mechanisms play a role: cytokine production, neutrophil activation, free radical generation, lipid peroxidation, and decreased number of endogenous free radical scavengers. ${ }^{3,4}$ The therapeutic or preventive approach to ischemia-reperfusion injury has been designed to directly counter these pathologic processes (eg, anti-tumor necrosis factor $\alpha$ antibodies ${ }^{5}$ ) or to augment defense systems with the addition of novel agents 
(eg, calcium channel blockers ${ }^{6}$ ) or endogenously produced substances (eg, superoxide dismutase ${ }^{7}$ ). Many of these treatments have resulted in prolonged lung preservation with good post-transplantation graft function in experimental models, but the elimination of ischemia-reperfusion injury in clinical lung transplantation remains a challenge.

Our approach to ameliorating ischemia-reperfusion injury uses captopril, an angiotensin-converting enzyme (ACE) inhibitor. Others have examined the effectiveness of captopril in lessening ischemia-reperfusion injury in heart and liver models. For example, Gurevitch and coworkers ${ }^{8}$ added captopril to the cardioplegic solution and administered it at reperfusion in an isolated rat heart model. After ischemia and reperfusion, the hearts that had received captopril had improved hemodynamic measures, increased coronary artery flow, and increased oxygen consumption. In a study of ischemia-reperfusion injury after liver transplantation, the investigators infused an ACE inhibitor, enalapril, before reperfusion and measured the sinusoidal perfusion rate, leukocyte adherence, and liver function (bile output, hepatic enzymes, and coagulation factors). Enalapril significantly reduced leukocyte adherence and improved all of the other parameters. ${ }^{9}$

The mechanism by which captopril exerts its protective effect is controversial and likely complex. Many have held captopril as an example of a free radical scavenger ${ }^{10}$ and an inhibitor of neutrophil activity, ${ }^{11}$ whereas others have provided evidence to the contrary. ${ }^{12}$ In this study we hypothesized that the addition of captopril to the lung flush preservation solution would (1) ameliorate ischemia-reperfusion injury, as assessed by blood oxygenation, peak airway pressure, and pulmonary edema, and (2) exert its protective effect through the reduction of neutrophil sequestration and lipid peroxidation.

\section{Methods}

Rat left single-lung transplantation model. Inbred male Lewis rats (250-300 g, 10-12 weeks old; Charles River Laboratories, Inc, Quebec, Canada) were used in all groups. The Institutional Animal Care and Use Committee of the Toronto General Hospital reviewed and approved the protocol for this study. All animals received humane care in accordance with the "Guide for the Care and Use of Laboratory Animals" (National Institutes of Health publication 85-23, revised 1985).

Organ retrieval procedure. Donor rats were anesthetized by intraperitoneal injection of $1 \mathrm{~mL}$ of sodium pentobarbital (Somnotol; MTC Pharmaceuticals, Cambridge, Ontario, Canada) and intubated through a tracheostomy with a 14gauge intravenous catheter. Animals were connected to a vol- ume-controlled ventilator (Harvard Rodent Ventilator, model 683; Harvard Apparatus Co, Inc, South Natick, Mass) and ventilated with an inspired oxygen fraction of 1 at 75 breaths $/ \mathrm{min}$, a tidal volume of $10 \mathrm{~mL} / \mathrm{kg}$, and a positive endexpiratory pressure of $2 \mathrm{~cm} \mathrm{H}_{2} \mathrm{O}$. A median laparosternotomy was then performed, and 300 USP of heparin (Hepalean; Organon Teknika, Toronto, Ontario, Canada) was injected into the inferior vena cava. For the retrieval of the heart-lung block, the inferior vena cava was incised, the left atrial appendage was truncated, and a 14-gauge cannula was placed through a right ventricular outflow tractotomy into the main pulmonary artery. The lungs were flushed through this cannula with $20 \mathrm{~mL}$ of either low-potassium dextran-glucose solution (LPDG; $\mathrm{n}=5$; Perfadex; Biophausia, Uppsala, Sweden) or LPDG plus captopril $(\mathrm{n}=5)$ at $4^{\circ} \mathrm{C}$. Tromethamine was added to both solutions to adjust the $\mathrm{pH}$ to 7.5. The flush solution in all groups contained $500 \mu \mathrm{g} / \mathrm{L}$ of alprostadil (prostaglandin $\mathrm{E}_{1}$; Prostin VR; Upjohn, Don Mills, Ontario, Canada). The study was conducted in a randomized blinded fashion. Immediately after the lungs were flushed, the endotracheal tube was clamped to keep the lungs inflated for the duration of storage, and the heart-lung block was excised. Care was taken to maintain hypothermic conditions, during which semirigid cuffs prepared from a 14-gauge cannula were placed into the pulmonary artery, pulmonary vein, and main bronchus. In each case the vessel or bronchus was drawn through the center of the cuff, everted circumferentially around it, and secured with a 7-0 polypropylene ligature. Each lung was then placed into $40 \mathrm{~mL}$ of LPDG or LPDG plus captopril solution for 18 hours at $4{ }^{\circ} \mathrm{C}$.

Captopril preservation and flush solution. Before the start of the study, captopril ( $500 \mu \mathrm{mol} / \mathrm{L}$; Sigma Chemical Co, St Louis, Mo) was dissolved in $500 \mathrm{~mL}$ of LPDG solution at room temperature, reintroduced into the bag through a 0.22 $\mu \mathrm{m}$ filter (Millex-GS; Millipore Corporation, Bedford, Mass), and stored at $4^{\circ} \mathrm{C}$. The resultant solution was colorless and indistinguishable from standard LPDG. In addition, there was no significant difference in the osmolarity between groups.

Transplantation procedure. Age-, sex-, strain-, and weightmatched recipient animals were anesthetized and intubated as described for donor animals. The animals' lungs were ventilated in a similar fashion. For measurement of the peak airway pressure after graft reperfusion, a 3-way tap was inserted between the endotracheal tube and the ventilator circuit and connected to a pressure transducer. The condition of the recipient was monitored by blood pressure measurement through a 22-gauge cannula placed in the right carotid artery. A left-sided thoracotomy was performed through the fifth intercostal space. The left lung was mobilized by dividing the pulmonary ligament. The hilum of the left lung was dissected, and the pulmonary artery, pulmonary vein, and the left main bronchus were identified and isolated. All 3 structures were clamped with microsurgical aneurysm clamps. All 3 structures were incised on their anterior aspect, and the 3 cuffs of the donor lung were placed into the equivalent recipient structures and fixed with a 7-0 polypropylene suture. 
After a standardized total warm ischemic time of 20 minutes, the transplanted lung was reinflated, and blood was reintroduced by releasing the pulmonary vein followed by the arterial clamps. Immediately after graft reperfusion, the recipient's native left lung was excised, and the transplanted lung was placed in the anatomic position in the chest. A 19-gauge drainage catheter (Butterfly-19; Abbott Laboratories Ltd, Saint Laurent, Quebec, Canada) was placed into the left pleural space to avoid accumulation of fluid in the chest. The thoracotomy was closed loosely, and the recipient animal was ventilated with an inspired oxygen fraction of 1.0, a rate of 75 breaths $/ \mathrm{min}$, a tidal volume of $10 \mathrm{~mL} / \mathrm{kg}$, and a positive endexpiratory pressure of $2 \mathrm{~cm} \mathrm{H}_{2} \mathrm{O}$ for 2 hours.

Nontransplanted flushed lungs. Left lungs that were flushed with LPDG and harvested from 5 Lewis rats were processed as nontransplanted flushed lungs for biochemical comparisons.

Measurement of lung graft function. Recipient systolic arterial blood pressure, peak airway pressure, and oxygenation of graft venous blood were assessed at the end of the 2hour reperfusion period. Blood was sampled under direct vision by means of a heparinized needle inserted into the pulmonary vein distal to the anastomotic cuff directed toward the donor lung.

Tissue samples. The lung was divided into thirds. The superior third was used for wet/dry weight ratio, the middle third was processed for myeloperoxidase (MPO) and $\mathrm{F}_{2}$-isoprostane analyses (snap frozen in liquid nitrogen and stored at $-70^{\circ} \mathrm{C}$ ), and the inferior third was used for histologic examination (fixed in $10 \%$ formalin and embedded in paraffin).

Wet/dry weight ratio. The superior third of the transplanted and reperfused lung was weighed and then placed in an oven at $100^{\circ} \mathrm{C}$ for 72 hours. After this drying procedure, the portion was reweighed, and the ratio of the weight before and after drying was calculated. This measure reflects lung water or pulmonary edema.

MPO activity assay. Lung tissue was assayed for MPO activity, an index of polymorphonuclear neutrophil sequestration, according to the method of Suzuki and coworkers. ${ }^{13}$ MPO activity was assessed at $37^{\circ} \mathrm{C}$ by monitoring the change in absorbance at $655 \mathrm{~nm}$ over a 3-minute period in a Cobas FARA II centrifugal analyzer (Roche Diagnostic Systems, Montclair, NJ). The reaction mixture contained $16 \mathrm{mmol} / \mathrm{L}$ 3,3',5,5'-tetramethylbenzidine dissolved in $N, N$-dimethlyformamide in $0.22 \mathrm{~mol} / \mathrm{L}$ phosphate buffer that contained $\mathrm{NaCl}$, $0.11 \mathrm{~mol} / \mathrm{L}$, at $\mathrm{pH} 5.4$. The reaction was initiated by the addition of hydrogen peroxide, $3 \mathrm{mmol} / \mathrm{L}$. One unit of activity was defined as a 1-unit change in absorbance per minute at $37^{\circ} \mathrm{C}$. Protein content of samples was determined by means of the bicinchoninic acid protein assay system (Pierce, Rockford, Ill). MPO activity is expressed as units per milligram of protein.

$F_{2}$-isoprostane tissue and serum levels. $F_{2}$-isoprostanes have been shown to be sensitive and accurate markers of tissue lipid peroxidation. ${ }^{14} \mathrm{~F}_{2}$-isoprostane levels were determined by means of an eicosanoid immunoassay with an acetylcholinesterase kit (Cayman Chemical, Ann Arbor, Mich). Samples of tissue $(0.3 \mathrm{~g})$ and plasma $(0.5 \mathrm{~mL})$ were spiked with 5000 disintegrations per minute of tritiumlabeled prostaglandin $\mathrm{F}_{2 \alpha}$. Tissue samples were blade homogenized in $1.0 \mathrm{~mL}$ of Hanks buffered salt solution without $\mathrm{Ca}^{++}-\mathrm{Mg}^{++}$phenol red at high speed on ice. Proteins $(0.5-\mathrm{mL}$ sample) were precipitated with $1 \mathrm{~mL}$ of $100 \%$ ethanol, allowed to stand at $4{ }^{\circ} \mathrm{C}$ for 5 minutes, and removed with centrifugation ( $1500 \mathrm{~g}$ for 10 minutes). The supernatant containing $\mathrm{F}_{2}$-isoprostanes was then decanted, an equal volume of $15 \% \mathrm{wt} / \mathrm{vol} \mathrm{KOH}$ was added, and samples were diluted to 5 $\mathrm{mL}$ with double-distilled water; the $\mathrm{pH}$ was lowered below 4 with hydrochloric acid. Samples were then passed through preconditioned SPE- $\mathrm{C}_{18}$ reverse-phase cartridges, followed by $5 \mathrm{~mL}$ of pure water and then $5 \mathrm{~mL}$ of high-performance liquid chromatography-grade hexane. $\mathrm{F}_{2}$-isoprostanes were eluted with $5 \mathrm{~mL}$ of ethyl acetate containing $1 \%$ methanol. The ethyl acetate was then evaporated with nitrogen. One milliliter of eicosanoid immunoassay resuspension buffer was added, and samples were placed in a vortex for $30 \mathrm{sec}-$ onds and sonicated on ice 3 times for 5 seconds. Samples were then separated for scintillation counting $(250 \mu \mathrm{L})$ and eicosanoid immunoassay $(100 \mu \mathrm{L})$ analysis.

The recovery factor was determined by dividing $4 \times$ disintegrations per minute of sample by the amount of tritiumlabeled prostaglandin $\mathrm{F}_{2 \alpha}$ added. $\mathrm{F}_{2}$-isoprostane levels in the extracted sample were determined by dividing the eicosanoid immunoassay (in picograms per milliliter) by the recovery factor. Total $\mathrm{F}_{2}$-isoprostane levels were determined by dividing the extracted $\mathrm{F}_{2}$-isoprostane levels by the volume $(500 \mu \mathrm{L})$ of the sample used for purification. Protein content of samples was determined by means of the bicinchoninic acid protein assay system (Pierce, Rockford, Ill), and tissue and serum levels of $\mathrm{F}_{2}$-isoprotanes are expressed as picograms per milligram of protein and picograms per milliliter of plasma.

Histologic analysis. The inferior third of the lungs was used for histologic examination 2 hours after reperfusion. Specimens were fixed in $10 \%$ formalin, dehydrated, embedded in paraffin, cut into 5- $\mu \mathrm{m}$ sections, and mounted. After the sections were deparaffinized, they were stained with hematoxylin and eosin. A pathologist blinded to the study analyzed the slides for hemorrhage, ischemic changes, inflammation, and edema.

Statistical analysis. Where the assumptions of homogeneity and normality were met, the $t$ test was used. Where these assumptions were not met, the Mann-Whitney $U$ test was used. The SigmaStat version 1.0 (SPSS, Inc, Chicago, Ill) software package was used for all statistical analyses.

\section{Results}

Physiologic function of the transplanted lung. All rats survived the transplant and 2-hour reperfusion period. Fig 1 demonstrates the significant differences in $\mathrm{Po}_{2}$, peak airway pressure, and wet/dry weight ratios between the captopril treatment group and the control 

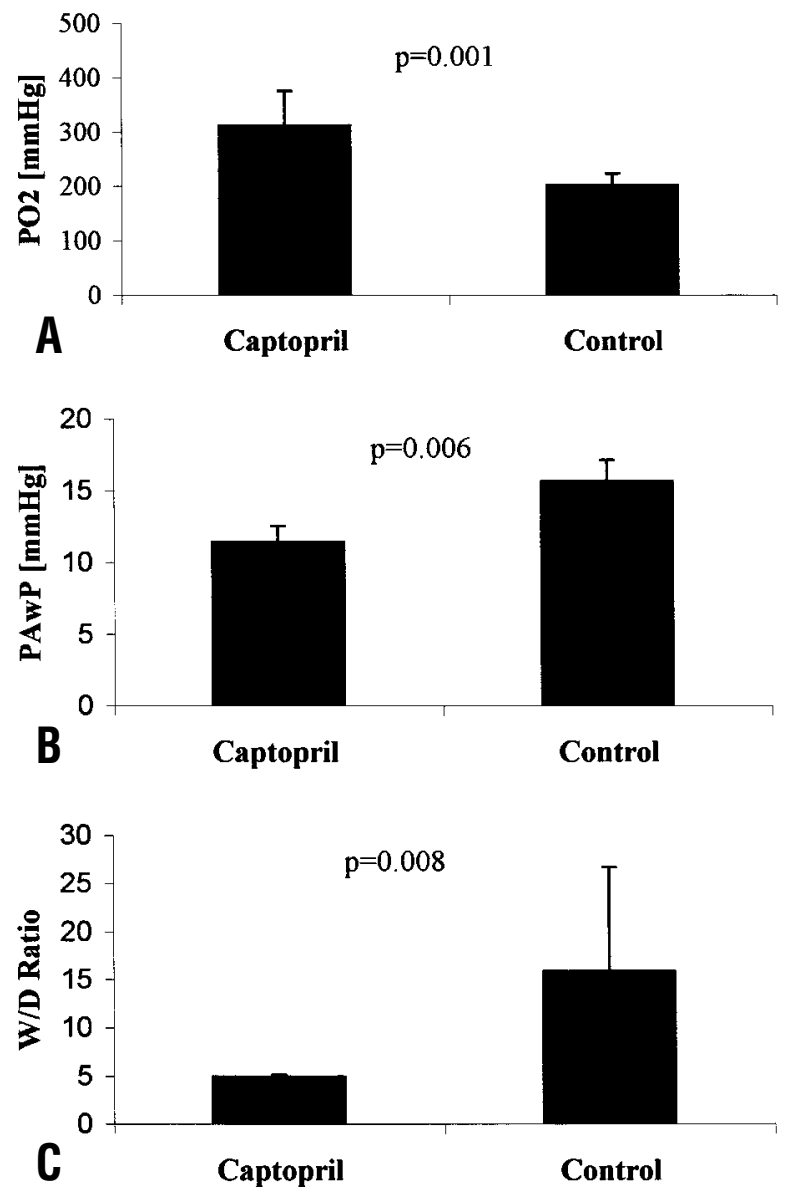

Fig 1. Physiologic assessment of transplanted lungs. Mean \pm $\mathrm{SD}$ of $\mathrm{Po}_{2}$ values $(\mathrm{A} ; P=.001)$, airway pressure values $(P A w P, \mathbf{B} ; P=.006)$, and wet/dry lung weight ratios $(W / D, \mathbf{C}$; $P=.008) 2$ hours after reperfusion $(\mathrm{n}=5)$.

group. All measurements were taken 2 hours after reperfusion. The $\mathrm{Po}_{2}$ was significantly improved in the captopril group $(312 \pm 63.3$ vs $202 \pm 21.1 \mathrm{~mm} \mathrm{Hg} ; P=$ .006). The peak airway pressure in the captopril treatment group was $11.4 \pm 1.1 \mathrm{~cm} \mathrm{H}_{2} \mathrm{O}$, whereas that measured in the control group was $15.6 \pm 1.5 \mathrm{~cm} \mathrm{H}_{2} \mathrm{O}(P=$ .001). Captopril treatment also resulted in a significantly lower wet/dry weight ratio ( $4.9 \pm 0.4$ vs $15.8 \pm 10.9$; $P=.008)$. No significant systolic blood pressure differences were noted at 2 hours after graft reperfusion between the groups $(P=.12)$.

Histologic analysis. Histologic sections from the control group showed signs of severe hemorrhagic congestion and interstitial edema, whereas sections from the captopril treatment group showed moderate congestion and less edema.

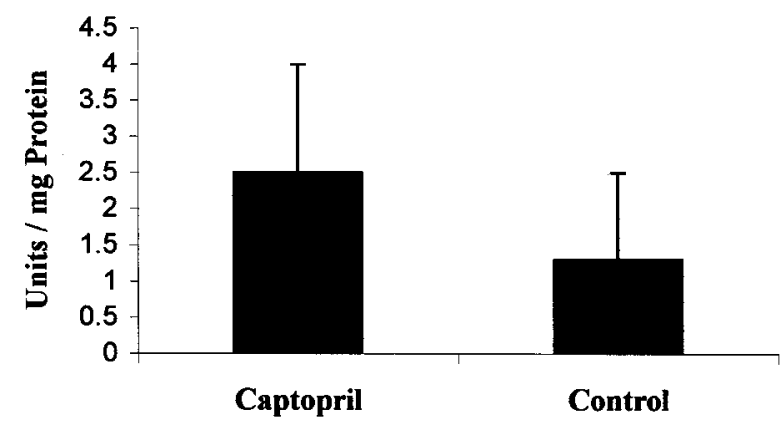

Fig 2. Mean \pm SD of tissue MPO activity 2 hours after reperfusion $(\mathrm{n}=5)$. There was no significant difference between groups $(P>.05)$.

MPO activity. MPO activity in nontransplanted lungs was $0.4 \pm 0.2 \mathrm{U} / \mathrm{mg}$ lung protein (Fig 2). After reperfusion, MPO activity in the captopril-treated group was not significantly different from that measured in the control group ( $2.5 \pm 1.5$ vs $1.3 \pm 1.2 \mathrm{U} / \mathrm{mg}$ lung protein).

Tissue and plasma $\mathbf{F}_{2}$-isoprostanes. The nontransplanted lungs had a mean $\mathrm{F}_{2}$-isoprostane level of 298.4 $\pm 58.6 \mathrm{pg} / \mathrm{mg}$ lung protein. There was no significant difference in lung tissue $\mathrm{F}_{2}$-isoprostane level between the captopril and the control groups $(325.0 \pm 96.9$ vs $200.8 \pm 58.6 \mathrm{pg} / \mathrm{mg}$ lung protein; Fig 3, A).

The nontransplanted rats had a mean serum $\mathrm{F}_{2}$-isoprostane level of $1.8 \pm 1.4 \mathrm{pg} / \mathrm{mL}$ plasma. There was no significant difference in serum level of $\mathrm{F}_{2}$-isoprostane between the captopril-treated group $(5.0 \pm 1.1 \mathrm{pg} / \mathrm{mL}$ plasma) and the control group $(3.7 \pm 2.5 \mathrm{pg} / \mathrm{mL}$ plasma; Fig 3, B).

\section{Discussion}

We used a rat single-lung transplantation model of ischemia-reperfusion injury to evaluate the protective effects of captopril. We found that the addition of captopril to the pulmonary preservation and flush solution during cold ischemia resulted in significantly improved oxygenation, peak airway pressure, and wet/dry weight ratios measured after 18 hours of cold storage and 2 hours of reperfusion. The mechanism by which captopril exerted these protective physiologic effects remains elusive. We had hypothesized that captopril would likely act as a free radical scavenger and inhibitor of neutrophil activation; however, our measures of $\mathrm{F}_{2}$-isoprostane tissue and plasma levels and MPO activity did not detect a significant ability of captopril to act in this way in transplanted lungs.

This model has proven useful for the study of interventions to protect against ischemia-reperfusion injury after lung transplantation. ${ }^{15}$ By using isogeneic rats, we 
can eliminate rejection as a confounding factor in the assessment. We preserved the lungs for an extended period of 18 hours to ensure that we had sufficiently severely injured lungs. We chose to examine the severity of the ischemia-reperfusion injury 2 hours after the start of reperfusion because this corresponds to a time point in the clinical setting when we frequently see evidence of this injurious process.

Captopril was selected because it has been shown in other models of ischemia-reperfusion injury to improve functional and biochemical measures. ${ }^{16}$ We added captopril to both the flush and preservation solution so it could protect the lung during the cold ischemic period. This is important in that Salahudeen and coworkers ${ }^{17}$ have shown that cold storage induces $\mathrm{F}_{2}$-isoprostane formation in an experimental kidney model where the organs were stored in University of Wisconsin solution. They were also able to effectively suppress the $\mathrm{F}_{2}$-isoprostane level in organs stored for 48 hours, with a lazaroid compound that was added to the storage solution. We chose LPDG as our preservation solution, because it is our current clinical and experimental standard of lung preservation for transplantation. We have previously demonstrated LPDG solution to be superior to Euro-Collins solution in a model of 12-hour pulmonary preservation. ${ }^{18}$

Captopril has been shown to have a wide range of activities, and it is likely that its ability to improve graft function after ischemia-reperfusion injury is due to one of these other mechanisms. ACE inhibition prevents bradykinin degradation. Matoba and coworkers ${ }^{19}$ examined the effects of ACE inhibition on hypoxia and reoxygenation injury in cardiac myocytes. Bradykinin and cilazaprilat (an ACE inhibitor) inhibited creatine kinase release, whereas an angiotensin receptor type 1 (AT1) inhibitor and angiotensin II did not. The ability of cilazaprilat to reduce this injury was eliminated when a bradykinin $\mathrm{B} 2$ receptor antagonist was added to the model. Therefore, cilazaprilat was likely protective through its ability to inhibit kininase II (bradykinin degradation) activity.

Others have hypothesized that captopril is protective in ischemia-reperfusion injury models because of its ability to increase blood flow by eliminating the vasoconstricting effect of angiotensin II. ${ }^{8}$ We noted no systemic hemodynamic differences (diastolic and systolic blood pressures) between the groups. This suggests that captopril added to the preservation solution did not affect systemic hemodynamics. We did not measure pulmonary artery pressure, but it is possible that the residue of captopril in the lung tissue exerted its effect on local vasoregulation.
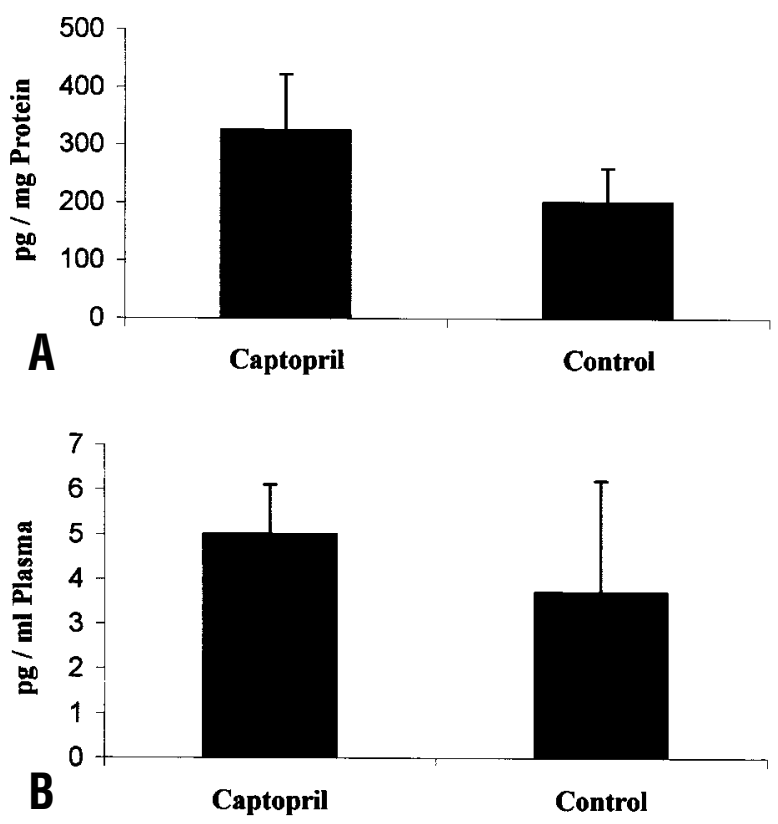

Fig 3. Mean $\pm \mathrm{SD}$ of tissue (A) and plasma (B) $\mathrm{F}_{2}$-isoprostane levels 2 hours after reperfusion. There were no significant differences between groups $(P>.05)$.

Another possible effect of ACE inhibition is a decrease in production of angiotensin II and therefore reduced activation of AT1 receptors. Yanagitani and coworkers ${ }^{20}$ examined AT1 receptor-mediated peroxide production in human macrophages. AT1 antagonism was able to decrease peroxide production in a dosedependent manner.

ACE inhibition and kininase II inhibition have a complex interaction with nitric oxide generation. Yang and coworkers ${ }^{21}$ used a model of myocardial ischemiareperfusion injury in endothelial nitric oxide synthase (eNOS) gene knockout mice to examine the effect of ACE inhibition in an attempt to elucidate the protective mechanism. In eNOS $+/+$ mice ACE inhibition was able to reduce myocardial infarct size, whereas in eNOS -/- mice this effect was abolished. Others have demonstrated that ACE inhibition can decrease postischemic leukocyte adhesion to endothelium. ${ }^{11} \mathrm{We}$ were unable to detect a difference in level of neutrophil sequestration in our 2 study groups.

The angiotensin system has recently been noted to have immunomodulatory interactions. Constantinescu and coworkers ${ }^{22}$ found that captopril and lisinopril are able to suppress the mononuclear cell production of interleukin 12, a proinflammatory $\mathrm{T}_{\mathrm{H}} 1$ cytokine. In another study, ACE inhibitors were able to suppress tumor necrosis factor $\alpha$ production in vitro and in 
vivo. ${ }^{23}$ The mechanism by which ACE is involved with cytokines is not clear. It is possible that captopril was protective in our model through interactions with the inflammatory or immune systems. We hypothesized that captopril would limit or prevent ischemia-reperfusion injury by scavenging free radicals and inhibiting neutrophil sequestration. To measure the effects of the drug, we used the MPO activity and $\mathrm{F}_{2}$-isoprostane assays. MPO activity is a measure of neutrophil sequestration. This oxygen-dependent enzyme is present in azurophilic granules in neutrophils, and it is responsible for eliminating bacteria, fungi, and foreign cells. ${ }^{24}$ $\mathrm{F}_{2}$-isoprostanes are the end products of lipid peroxidation reactions. These substances are produced by the action of noncyclooxygenase-oxidative modifications of arachidonic acid that occur after free radical attack of phospholipids. ${ }^{25}$ They circulate in the plasma and are excreted in the urine after phospholipase-dependent release from activated cells. Only the MPO assay has been previously studied in conjunction with ACE inhibitors. Hoshida and coworkers ${ }^{26}$ used a rabbit model of myocardial infarction caused by coronary occlusion and reperfusion. They administered quinapril, an ACE inhibitor, over a prolonged period to see whether this would ameliorate the injury. They measured a decrease in MPO activity in the treatment group compared with the control group and hypothesized that the ACE inhibitor limited the interaction between leukocytes and the endothelium and therefore lessened the injury. Others have measured the effect of ACE inhibitor administration on lipid peroxidation by thiobarbituric acid-reactive substance production assay and have noted a significant decrease. The $\mathrm{F}_{2}$-isoprostane assay has not previously been used as a measure of free radical lipid peroxidation after ACE inhibition. It is also possible that captopril scavenged free radicals but not those that cause lipid peroxidation. Becker and coworkers ${ }^{27}$ addressed the relationship between $\mathrm{F}_{2}$-isoprostane levels and oxygen-derived free radical generation by noting that it is indeed possible for free radicals to damage vascular barriers without altering $\mathrm{F}_{2}$-isoprostane generation.

ACE inhibitors can be divided into 2 groups: nonsulfhydryl and sulfhydryl. The importance of this distinction in the discussion of ischemia-reperfusion injury is that sulfhydryl groups have been shown to scavenge free radicals more effectively than agents without sulfhydryl groups. ${ }^{28}$ However, this area is controversial with evidence both supporting and refuting the functional importance of the sulfhydryl group. One study examined the protective effects of 2 substances with sulfhydryl groups in a mouse model of viral myocarditis. Suzuki and coworkers ${ }^{29}$ found that both captopril and a sulfhydryl-containing amino acid derivative without ACE-inhibiting properties significantly improved survival and myocardial injury but paradoxically reduced the expression of superoxide dismutase messenger RNA. Another study compared the ability of sulfhydryl- and nonsulfhydryl-containing ACE inhibitors to inhibit hydroxyl radical production by using electron spin resonance and 5,5-dimethyl-L-pyrroline$\mathrm{N}$-oxide as the spin trap. They found that both groups of ACE inhibitors were capable of scavenging hydrox$\mathrm{yl}$ radicals and therefore concluded that this scavenger ability is likely not related to the presence of the sulfhydryl group. ${ }^{30}$ Chopra and coworkers ${ }^{31}$ examined the ability of ACE inhibitors to scavenge free radicals and prevent lipid peroxidation by using a free radical generation and a microsomal thiobarbituric acid-reactive substance production assay. They showed that the sulfhydryl presence on ACE inhibitors resulted in effective free radical scavenging but that either type of ACE inhibitor was effective in inhibiting lipid peroxidation.

It is possible that some additional beneficial effects may have been seen if captopril had been administered to the recipient to ensure systemic levels of the drug at the time of graft reperfusion. However, we did not infuse captopril intravenously for a number of reasons. First, the nature of the lung transplantation procedure is such that a significant drop in systemic blood pressure with the addition of the captopril intravenously would not be well tolerated by the animals. Direct infusion into the pulmonary artery in this model would also be technically difficult and would put the procedure at risk. However, given the damaging effect of reperfusion, the presence of the protective substance at this point would likely be beneficial. In addition, we do not know whether the effect of captopril occurs during ischemia or whether captopril diffuses into the parenchyma and acts at the time of reperfusion. To fully understand when and where captopril administration is best suited, we need to understand the mechanism of its action in this setting.

In summary, we have shown that captopril in the preservation and flush solution in a rat single-lung transplant model decreased the severity of ischemiareperfusion injury, as demonstrated by significantly improved oxygenation, peak airway pressure, and posttransplantation pulmonary edema. We were unable to ascertain which mechanism was responsible for the beneficial effects seen, but we were able to provide evidence against the hypothesis that captopril is a free radical scavenger in this setting. Our attention should turn 
toward the other possible mechanisms of ACE inhibitors. This might ultimately provide further insight into the link between acute lung injury and chronic graft dysfunction. Our ultimate goal is to be able to apply this simple modification of lung preservation solutions to the clinical setting to improve lung function after transplantation.

We thank Dr J. Mates for his expert technical assistance in performing the animal procedures; S. A. Nicholson, BSc, and Dr T. Lindsay for assistance in performing the MPO and $\mathrm{F}_{2}$-isoprostane assays; and Dr Peter Lewycky, who reviewed statistical analysis of this study as a biostatistician.

\section{REFERENCES}

1. Hosenpud JD, Bennett LE, Keck BM, Fiol B, Boucek MM, Novick RJ. The Registry of the International Society for Heart and Lung Transplantation: sixteenth official report-1999. J Heart Lung Transplant 1999;18:611-26.

2. Haydock DA, Trulock EP, Kaiser LR, Ettinger NA, Triantifillou AN, Ochoa LL, et al. Lung transplantation: analysis of thirty-six consecutive procedures performed over a twelvemonth period. The Washington University Lung Transplant Group. J Thorac Cardiovasc Surg 1992;103:329-40.

3. Ambrosio G, Tritto I. Reperfusion injury: experimental evidence and clinical implications. Am Heart J 1999;138:69-75.

4. Grace PA. Ischaemia-reperfusion injury. Br J Surg 1994;81:63747.

5. Khimenko PL, Bagby GJ, Fuseler J, Taylor AE. Tumor necrosis factor-alpha in ischemia and reperfusion injury in rat lungs. $\mathrm{J}$ Appl Physiol 1998;85:2005-11.

6. Sasaki S, Yasuda K, McCully JD, LoCicero J 3rd. Calcium channel blocker enhances lung preservation. J Heart Lung Transplant 1999;18:127-32.

7. Cremer J, Jurmann M, Dammenhayn L, Wahlers T, Haverich A, Borst HG. Oxygen free radical scavengers to prevent pulmonary reperfusion injury after heart-lung transplantation. J Heart Transplant 1989;8:330-6.

8. Gurevitch J, Pevni D, Frolkis I, Matsa M, Paz Y, Mohr R, et al. Captopril in cardioplegia and reperfusion: protective effects on the ischemic heart. Ann Thorac Surg 1997;63:627-33.

9. Anthuber M, Farkas S, Rihl M, Menger MD, Schildberg FW, Jauch KW, et al. Angiotensin-converting enzyme inhibition by enalapril: a novel approach to reduce ischemia/reperfusion damage after experimental liver transplantation. Hepatology 1997;25:648-51.

10. Engelman RM, Rousou JA, Iyengar J, Das DK. Captopril, an ACE inhibitor, for optimizing reperfusion after acute myocardial infarction. Ann Thorac Surg 1991;52:918-26.

11. Kupatt C, Habazettl H, Zahler S, Weber C, Becker BF, Messmer $\mathrm{K}$, et al. ACE-inhibition prevents postischemic coronary leukocyte adhesion and leukocyte-dependent reperfusion injury. Cardiovasc Res 1997;36:386-95.

12. Johnson P, Wei Y, Huentelman MJ, Peters CM, Boldyrev AA. Hydralazine, but not captopril, decreases free radical production and apoptosis in neurons and thymocytes. Free Radic Res 1998;28:393-402.

13. Suzuki K, Ota H, Sasagawa S, Sakatani T, Fujikura T. Assay method for myeloperoxidase in human polymorphonuclear leukocytes. Anal Biochem 1983;132:345-52.

14. Morrow JD, Harris TM, Roberts L. Noncyclooxygenase oxidative formation of a series of novel prostaglandins: analytical ramifications for measurement of eicosanoids. Anal Biochem 1990;184:1-10.

15. Hiratsuka M, Yano M, Mora BN, Nagahiro I, Cooper JD, Patterson GA. Heat shock pretreatment protects pulmonary isografts from subsequent ischemia-reperfusion injury. J Heart Lung Transplant 1998;17:1238-46.

16. Vargas AV, Robinson AV, Schulak JA. Captopril amelioration of renal reperfusion injury. J Surg Res 1994;57:28-32.

17. Salahudeen A, Nawaz M, Poovala V, Kanji V, Wang C, Morrow $\mathrm{J}$, et al. Cold storage induces time-dependent $\mathrm{F} 2$-isoprostane formation in renal tubular cells and rat kidneys. Kidney Int 1999;55:1759-62.

18. Keshavjee SH, Yamazaki F, Cardoso PF, McRitchie DI, Patterson GA, Cooper JD. A method for safe twelve-hour pulmonary preservation. J Thorac Cardiovasc Surg 1989;98:529-34.

19. Matoba S, Tatsumi T, Keira N, Kawahara A, Akashi K, Kobara $\mathrm{M}$, et al. Cardioprotective effect of angiotensin-converting enzyme inhibition against hypoxia/reoxygenation injury in cultured rat cardiac myocytes. Circulation 1999;99:817-22.

20. Yanagitani Y, Rakugi H, Okamura A, Moriguchi K, Takiuchi S, Ohishi M, et al. Angiotensin II type 1 receptor-mediated peroxide production in human macrophages. Hypertension 1999;33:335-9.

21. Yang XP, Liu YH, Shesely EG, Bulagannawar M, Liu F, Carretero OA. Endothelial nitric oxide gene knockout mice: cardiac phenotypes and the effect of angiotensin-converting enzyme inhibitor on myocardial ischemia/reperfusion injury. Hypertension 1999;34:24-30.

22. Constantinescu CS, Goodman DB, Ventura ES. Captopril and lisinopril suppress production of interleukin-12 by human peripheral blood mononuclear cells. Immunol Lett 1998;62:2531.

23. Fukuzawa M, Satoh J, Sagara M, Muto G, Muto Y, Nishimura S, et al. Angiotensin converting enzyme inhibitors suppress production of tumor necrosis factor-alpha in vitro and in vivo. Immunopharmacology 1997;36:49-55.

24. Lanza F. Clinical manifestation of myeloperoxidase deficiency. J Mol Med 1998;76:676-81.

25. Patrono C, Fitzgerald GA. Isoprostanes: potential markers of oxidant stress in atherothrombotic disease. Arterioscler Thromb Vasc Biol 1997; 17:2309-15.

26. Hoshida S, Yamashita N, Kawahara K, Kuzuya T, Hori M. Amelioration by quinapril of myocardial infarction induced by coronary occlusion/reperfusion in a rabbit model of atherosclerosis: possible mechanisms. Circulation 1999;99:434-40.

27. Becker PM, Sanders SP, Price P, Christman BW. F2-isoprostane generation in isolated ferret lungs after oxidant injury or ventilated ischemia. Free Radic Biol Med 1998;25:703-11.

28. Fernandes AC, Filipe PM, Freitas JP, Manso CF. Different effects of thiol and nonthiol ACE inhibitors on copper- induced lipid and protein oxidative modification. Free Radic Biol Med 1996;20:507-14.

29. Suzuki H, Matsumori A, Matoba Y, Kyu BS, Tanaka A, Fujita J, et al. Enhanced expression of superoxide dismutase messenger RNA in viral myocarditis: an SH-dependent reduction of its expression and myocardial injury. J Clin Invest 1993;91:2727-33. 
30. Suzuki S, Sato H, Shimada H, Takashima N, Arakawa M. Comparative free radical scavenging action of angiotensin-converting enzyme inhibitors with and without the sulfhydryl radical. Pharmacology 1993;47:61-5.

31. Chopra M, Beswick H, Clapperton M, Dargie HJ, Smith WE,
McMurray J. Antioxidant effects of angiotensin-converting enzyme (ACE) inhibitors: free radical and oxidant scavenging are sulfhydryl dependent, but lipid peroxidation is inhibited by both sulfhydryl- and nonsulfhydryl- containing ACE inhibitors. J Cardiovasc Pharmacol 1992;19:330-40.

\section{ON THE MOVE?}

Don't miss a single issue of the journal! To ensure prompt service when you change your address, please photocopy and complete the form below.

Please send your change of address notification at least six weeks before your move to ensure continued service. We regret we cannot guarantee replacement of issues missed due to late notification.

\section{JOURNAL TITLE:}

Fill in the title of the journal here.

\section{OLD ADDRESS:}

Affix the address label from a recent issue of the journal here.

\section{NEW ADDRESS:}

Clearly print your new address here.

Name

Address

City/State/ZIP
COPY AND MAIL THIS FORM TO:

Mosby

Subscription Customer Service

6277 Sea Harbor Dr

Orlando, FL 32887
OR FAX TO:

407-363-9661

N/ Mosby
OR PHONE:

800-654-2452

Outside the U.S., call

407-345-4000 